\title{
INOVAÇÕES EM PROCESSOS DE TECNOLOGIA: UM ESTUDO DE CASO EM UMA EMPRESA DE CONTABILIDADE DA CIDADE DO NATAL/RN
}

\author{
L. P. D. PAULA' ${ }^{1}$, M. F. DANJOUR ${ }^{2}$, B. C. MEDEIROS ${ }^{2 *}$ e M. E. M. AÑEZ ${ }^{3}$ \\ ${ }^{1}$ Serviço Brasileiro de Apoio às Micro e Pequenas Empresas - SEBRAE \\ ${ }^{2}$ Instituto Federal de Educação, Ciência e Tecnologia do Rio Grande do Norte \\ ${ }^{3}$ Universidade Federal do Rio Grande do Norte \\ bruno.campelo@ifrn.edu.br*
}

Artigo submetido em julho/2015 e aceito em outubro/2015

DOI: $10.15628 /$ holos. 2015.3200

\section{RESUMO}

O presente estudo tem como objetivo geral analisar os benefícios das inovações em processos, através do uso do sistema de informação e da tecnologia da informação. Quanto aos procedimentos metodológicos, foi realizado um estudo de caso único, em uma empresa de contabilidade, através de estudo predominantemente qualitativo, por meio da análise de conteúdo e avaliação de médias. Para a obtenção dos dados, foi utilizado o questionário, denominado de radar da inovação, baseado em Bachmann e Destefani (2008) e uma entrevista semiestruturada, tendo, como base, o estudo de Rezende (2005). Os resultados encontrados estão de acordo com a literatura existente, o qual identificou um número significativo de benefícios que a inovação de processos, através dos sistemas de informação e da tecnologia da informação, traz para uma organização. Além disso, os resultados demonstram que a empresa, objeto de estudo, apresenta um alto grau de inovação em processos, medida através do radar da inovação e este destaque é resultado do número de benefícios que são alcançados através da tecnologia da informação. Logo, a necessidade das empresas contábeis inovarem em processos é fundamental para o crescimento e a sustentabilidade dessas empresas. As mudanças estão acontecendo de uma maneira rápida, sendo necessário que as organizações acompanhem este cenário e se adaptem a esta realidade, realizando inovações, principalmente nos processos das empresas.

PALAVRAS-CHAVE: Inovação. Inovação em processos. Escritório de Contabilidade.

\section{INNOVATIONS IN TECHNOLOGY PROCESSES: A CASE STUDY IN AN ACCOUNTING FIRM IN THE CITY OF NATAL/RN}

\begin{abstract}
This study aims to analyze the general benefits of innovations in processes, through the use of the information system and information technology. Regarding the methodological procedures, a case study was conducted only in an accounting firm, through predominantly qualitative study, through content analysis and evaluation of medium. To obtain the data, the questionnaire was used, called innovation radar, based in Bachmann and Destefani (2008) and a semistructured interview, taking as a basis, the study of Rezende (2005). The results are in line with the existing literature, which identified a number of significant benefits that innovation processes, information systems
\end{abstract}

and information technology, brings to an organization. In addition, the results show that the company, object of study, presents a high degree of innovation in processes, measured by the radar innovation and this prominence is the result of the number of benefits that are achieved through information technology. Soon, the need of accounting firms innovate in processes is critical to the growth and sustainability of these companies. The changes are happening quickly, requiring that organizations follow this scenario and to adapt to this reality, making innovations, especially in the processes of companies.

KEYWORDS: Innovation, Innovation in process. Accounting Office. 


\section{INTRODUÇÃO}

A contabilidade surgiu como um sistema de escrituração, relacionado à necessidade de controle de bens e patrimônio. Desde então, ela passou por um processo lento de modificação, evoluindo, enquanto ciência, até chegar à forma de controle atual, ampliando seu campo de atuação.

Desta forma, os conceitos diversificados permitem desenvolver com mais discernimento e concisão a aplicação dessa ciência nos mais variados estilos e modalidades, fazendo a devida adaptação em cada uma das situações organizacionais. Neste processo, a contabilidade foi adquirindo espaço no cenário econômico brasileiro, na forma em que foi exigido elevado controle sobre o patrimônio e como resultado foram criados normas técnicas e princípios, para que essa ciência na sua forma profissional seguisse os avanços do contexto financeiro e socioeconômico na sua forma de orientação e controle da atividade contábil sobre diversas perspectivas, como, por exemplo, nos procedimentos de custos (BEUREN, 1993).

A expansão dos profissionais da contabilidade pode ser observada a partir de uma análise entre três anos, sobre a evolução dos Contadores Registrados no CFC/CRCs no Brasil. Segundo Conselho Federal de Contabilidade - CFC (2014), no período entre 2009 e 2013, houve uma evolução de $80 \%$ dos profissionais da contabilidade no Brasil, ocorrendo também uma evolução de $67 \%$ no número de contadores formados e uma redução de 1,5\% na quantidade de técnicos de contabilidade. No estado do Rio Grande do Norte também se figura este cenário. Ao avaliar o período de 2009 e 2013, percebe-se que houve uma evolução de $73 \%$ dos profissionais da contabilidade, com uma evolução de $57 \%$ no número de contadores formados e uma redução de $21,84 \%$ na quantidade de técnicos de contabilidade. Esses resultados comprovam a evolução na quantidade de profissionais da contabilidade no país e no estado do RN e demonstra também o aumento dos profissionais com curso superior e a redução nos profissionais com nível técnico (CFC, 2014).

Com as modificações no âmbito mundial em virtude da globalização, as informações referentes às empresas são transmitidas com maior velocidade e a contabilidade necessita acompanhar estes avanços (REIS E SILVA, 2007). Sendo assim, há uma necessidade eminente dos profissionais da contabilidade em se manterem em constante capacitação, adaptando-se às novas mudanças. Neste cenário, é fundamental que as organizações invistam em sistemas de informações e tecnologia, pois estes fazem com que as empresas se tornem cada vez mais ágeis, eficientes e eficazes. Os sistemas de informação são necessários para otimizar os fluxos de conhecimento e informações dentre e dentro das organizações.

A tecnologia da informação não se limita às questões relacionadas apenas ao uso de equipamentos ou de tecnologias avançadas. Trata-se, portanto, de uma área em que a cada dia desempenha um papel mais importante dentro das organizações públicas ou privadas, vinculadas a sistemas informatizados. Desta forma, pode-se considerar que a implantação de ferramentas de tecnologia da informação pode servir não apenas de suporte às atividades do negócio e as estratégias atuais, como também na criação de novas estratégias, ajudando, assim, no processo 
decisório organizacional e no seu posicionamento perante o mercado (HENDERSON; VENKATRAMAN, 1993; MENDONÇA et al., 2013).

Com o desenvolvimento dos sistemas de informação, a atuação do profissional da contabilidade foi modificada, e os procedimentos contábeis foram se tornando mais informatizados. Na visão de Grzeszezeszyn (2005), a contabilidade gerencial, por exemplo, vem se desenvolvendo ao ponto de ser aplicada do ponto de vista estratégico, no esforço de profissionais em propiciar novas práticas relacionadas às informações em tempo e relevância capazes de gerar maior segurança durante o processo de construção a estratégia organizacional. Por meio dos sistemas de informação, as organizações poderão obter, dentre outros benefícios, informações mais precisas, agilidade no processo decisório e melhor produtividade no processo contábil (GRZESZEZESZYN, 2005; ANDRADE et al., 2007).

Dessa forma, o presente estudo tem como objetivo geral analisar os benefícios das inovações em processos na empresa Métodos Contabilidade, através do uso do sistema de informação e da tecnologia da informação. Além desta parte introdutória, o presente artigo está composto pela fundamentação teórica, no qual são discutidos no capítulo 2 os conceitos de sistemas de informação e sua influencia nas práticas contábeis, e, além disso, serão abordados os conceitos de inovação em processos e sua relação com o uso da tecnologia da informação. Em seguida, tem-se o capítulo 3, composto pela metodologia, no qual discutirá os métodos utilizados para a realização deste estudo. O capítulo 4 apresenta os principais resultados acerca do estudo realizado, e, por fim, as considerações finais.

\section{REVISÃO BIBLIOGRÁFICA}

\subsection{Sistema de informação e a prática contábil}

Os sistemas de informação têm como principal elemento o poder da informação que é de suma importância para as empresas. O objetivo principal do sistema de informação é tratar e armazenar os dados, fornecendo informações e apoiando os processos de uma empresa. Segundo Rezende e Abreu (2000), os sistemas de informação são sistemas que produzem ou geram informações para a execução de ações, bem como para auxiliar processos de tomada de decisão.

Para Laudon e Laudon (2004), pode-se definir um sistema de informação como um conjunto de elementos que estão inter-relacionados, coletando ou recuperando, armazenando, distribuindo e processando informações para a tomada de decisões, além de contribuir para a coordenação e o controle de uma organização. Além de dar suporte à tomada de decisões, à coordenação e ao controle dos processos organizacionais, esses sistemas também auxiliam os gerentes e trabalhadores a analisar problemas e criar novos produtos.

Santos (2012) conceitua de forma similar, ao considerar que um sistema de informação é um grupo de componentes inter-relacionados que operam para atingir uma meta comum, mediante a aceitação de entradas e produção de saídas em um processo organizado. Assim todos convergem quando trata a importância do sistema informação no auxílio à tomada de decisão. 
O sistema de informação nos escritórios de contabilidade é a ferramenta fundamental para o funcionamento das atividades da empresa, pois a partir destas informações, que são geradas e tratadas com uma maior velocidade, pode-se garantir uma maior agilidade e confiabilidade nos processos dos escritórios. Neste caso, deve-se considerar que a abordagem sistêmica proporcionada pelos sistemas de informação à contabilidade permite identificar e mensurar, gerando decisões e julgamentos adequados por parte dos usuários das informações contábeis (MARION, 2014).

O sistema de informação integrado é visto como a união de elementos que se interagem entre os setores com o intuito de alcançar as metas e objetivos. Este sistema possui componentes como: entrada, que abrange reunião e captação de elementos que ingressam no sistema para serem processados; processamento, que converte a entrada em produto; e a saída, que abrange a transferência de componentes produzidos até o destino final (CORREIA, 2013).

Um dos reflexos do desenvolvimento tecnológico na Contabilidade pode ser verificado no aumento do grau de automação. Tarefas que anteriormente eram realizadas por processos manuais, já são desenvolvidas dentro de softwares mais específicos. Com isso os fluxos de documentos e papéis são reduzidos na empresa, além das modificações nas rotinas mais frequentes, como os lançamentos de débito e créditos, balancetes mensais, escrituração de livros fiscais, Demonstração do Resultado do Exercício e outros passaram a ser efetuadas dentro dos sistemas (PADOVEZE, 2000).

Convergindo com os autores, os contadores que utilizam os sistemas de informação na sua prática diária da contabilidade conseguem auferir uma visão sistêmica das informações, especialmente quando essas informações estão integradas, garantindo uma maior agilidade nas atividades e acompanhando em tempo ágil as atualizações fiscais que ocorrem no âmbito das suas atividades.

Conforme Rezende e Abreu (2000) os benefícios que as empresas buscam obter através dos sistemas de informação podem ser vistos como a oferta de melhores serviços e a obtenção de uma maior vantagem competitiva, contribuição na inteligência organizacional, auxílio à tomada de decisão útil, produtos de melhor qualidade, crescimento da rentabilidade e novas oportunidades de negócios, maior segurança nas informações, melhor precisão e minimização de erros, aperfeiçoamento nos sistemas, redução de custos, redução da carga de trabalho, melhor eficiência e eficácia e muitos outros benefícios que torna significativamente imprescindível a utilização dos sistemas de informação na prática contábil.

De acordo com o exposto, podem-se observar características das inovações em processos presentes nos sistemas de informação. Para compreender a relação das inovações em processos com os sistemas de informação, o qual a tecnologia da informação esta inserida, têm-se estas questões debatidas no próximo tópico.

\subsection{Inovação em processos com o uso da tecnologia da informação}

No cenário atual de significativa competitividade, é imprescindível desenvolver produtos e realizar uma prestação de serviço de qualidade, minimizando o retrabalho e de forma inovadora. 
Com isso, é necessário unir criatividade, método, inovação e ferramentas de qualidade para manter uma diferenciação no mercado. Muitas empresas já passaram pela fase inicial de gestão das organizações, e agora, além dessa fase, a inovação e o elevado desempenho são motivação e da garantia da qualidade, em que as certificações e também a padronização dos processos contribuíram para garantir diferenciais competitivos para a organização (PIERRY, 2001).

É importante ressaltar que o significado para "inovação" não está associado apenas à criação de novos produtos ou processos sofisticados. Grande parte das inovações pode vir de ideias simples e adotadas parcialmente. Neste caso, elas são conhecidas como inovações incrementais (SOUZA, 2011).

Conforme explica a Organização para a Cooperação e Desenvolvimento Econômico (OCDE, 2007), inovar em processos é utilizar métodos de produção novos ou significativamente melhorados, abrangendo métodos de entrega de produtos. Esses métodos podem envolver modificações na organização ou no equipamento da produção, além de uma união dessas mudanças, podendo derivar da utilização de novo conhecimento (OCDE, 2007). Os métodos podem ter a finalidade de entregar ou produzir produtos tecnologicamente novos ou aprimorados, os quais podem não ser entregues ou produzidos através dos métodos convencionais de produção, ou almejar maximizar a produção ou manter a eficiência na entrega de produtos existentes.

Já para Scholtissek (1959) as inovações nos processos envolvem processos novos ou adaptados que vinculam diferentes fatores e atividades. Elas são praticadas com o intuito de criar novos produtos ou serviços, ou para aumentar a qualidade, reduzir custos dos produtos ou serviços e elevar a rapidez. Neste sentido, diferente das inovações em produtos, as inovações em processos são mais difíceis de serem identificadas no mercado, e, portanto, são mais protegidas de imitação ou de serem copiadas (LONGANEZI, 2008).

Relacionando os objetivos das inovações em processos a partir das considerações propostas pela OCDE (2007), e dos autores mensurados com os benefícios dos sistemas de informação, segundo os autores abordados, pode-se observar que os sistemas de informação são exemplos claros de inovações em processos, garantindo uma maior rapidez das operações, redução de custos, criação de novos serviços ou melhoria dos mesmos e uma maior produtividade.

A tecnologia da informação pode ser considerada uma aglutinação de recursos tecnológicos e computacionais com o propósito de geração, armazenamento e o uso da informação, caracterizando-se um conjunto de todas as atividades equipadas com recursos computacionais. Seu significado pode até ser interpretado em um sentido mais amplo, a TI relaciona-se a diversos sistemas de informação, gestão e operadores de uma organização.

Kirchmer (2010) coloca a tecnologia da informação como um dos pilares para o gerenciamento do ciclo de vida dos processos organizacionais, tendo, como objetivos principais, a inovação e a agilidade. Segundo o autor, todas as fases do ciclo de vida precisam estar alinhadas as estes dois objetivos, conforme a Figura 1 abaixo: 


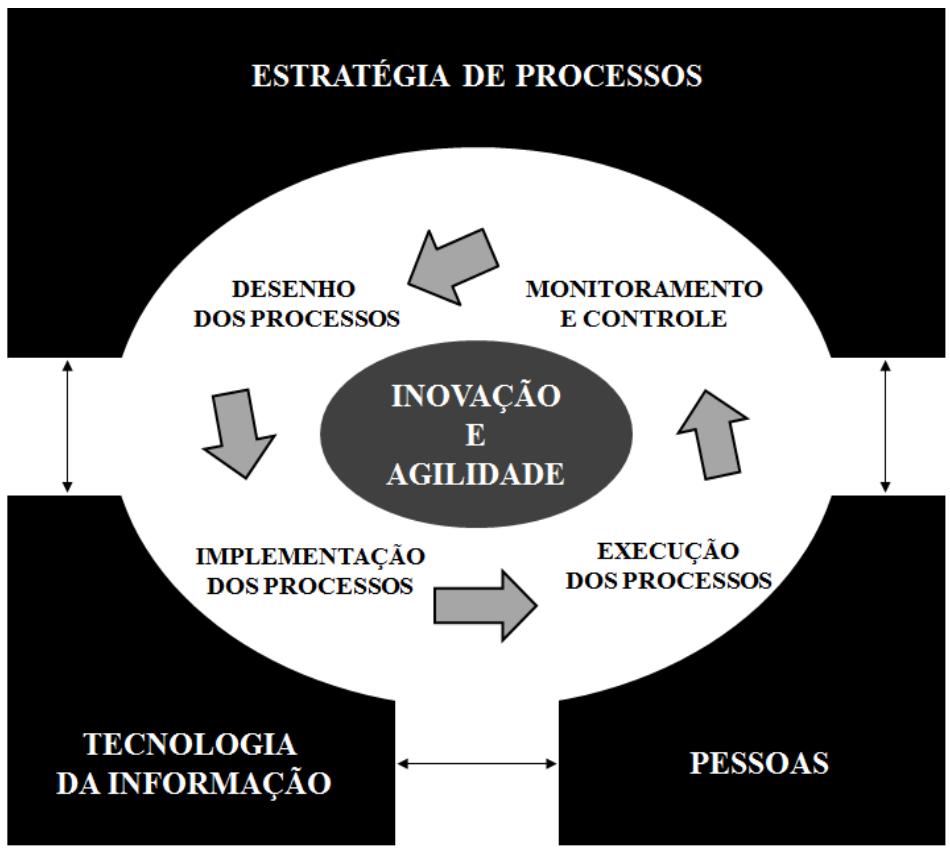

Figura 1 - Gestão da excelência dos processos Fonte: adaptado de Kirchmer (2010)

Segundo Kirchmer (2010), para se ter uma gestão adequada dos processos, é necessário, antes de tudo, ter uma estratégia adequada dos processos, que traduzem a estratégia global da organização. Em seguida, as inovações e seus impactos gerais são definidos, proporcionando uma base para a definição da estrutura dos processos e dos objetivos relacionados a eles, realizados na fase de desenho dos processos. Na fase de implementação, a organização deve passar por um processo de mudança e preparação dos recursos humanos e de TI para alcançar a inovação e a agilidade destes processos. Na execução, os processos são efetuados com base na implementação destes recursos, e, na etapa posterior, se tem o monitoramento e controle destes processos. Percebe-se, então, a relevância da TI como recurso fundamental de infraestrutura e base para o desenvolvimento e a inovação dos processos organizacionais.

Ao verificar a intercessão dos sistemas de informação com a tecnologia da informação, define-se a TI como um conjunto de software, hardware, recursos humanos e respectivos procedimentos que antecedem e sucedem o software (REZENDE; ABREU, 2000). Uma relação de aplicabilidade continuada, onde a tecnologias e sistemas da informação caminham juntos na constante do desenvolvimento no cenário tecnológico organizacional.

\section{METODOLOGIA}

Para a investigação do problema em estudo foi utilizada a pesquisa descritiva que segundo Michael (2009, p. 44) "se propõe a verificar e explicar problemas, fatos, ou fenômenos da vida real, com a precisão possível, observando e fazendo relações, conexões, à luz da influência que o ambiente exerce sobre eles". Em se tratando da natureza da ciência social, este estudo constitui em sua essência uma abordagem paradigmática funcionalista, pois aborda o sujeito de um ponto de vista objetivista, voltado para explanações racionais de assuntos sociais (BURREL; MORGAN, 1979).

Essa forma de pesquisa não faz interferência no ambiente inserido, sua finalidade é relatar os fenômenos, relacionando-os com o ambiente. Quanto aos procedimentos foi realizado um 
estudo de caso, o qual se retrata como um tipo de investigação empírica que investiga um fenômeno contemporâneo inserido no contexto da vida real, principalmente quando os limites entre o contexto e o fenômeno não se apresentam concretamente definidos (YIN, 2005). Esse procedimento demostram uma maior abrangência no estudo e inclui tanto estudos de casos múltiplos quanto de caso único.

Com relação à natureza da pesquisa, esta pode ser considerada qualitativa. O estudo qualitativo, segundo Flick (2009, p. 23) apresenta como aspectos essenciais "a escolha adequada de métodos e teorias convenientes; no reconhecimento e análise de diferentes perspectivas; nas reflexões dos pesquisadores a respeito de suas pesquisas como parte do processo de produção de conhecimento". Conforme Yin (2005), a pesquisa qualitativa considera que existe uma relação dinâmica, contextual, particular e temporal entre o objeto de estudo e o pesquisador, em virtude disto, necessita de uma interpretação dos fenômenos à luz dos fatos, do tempo e do contexto. $O$ ambiente real é o local concreto para obtenção dos dados, e a competência do pesquisador de interpretar a realidade, com isenção lógica, tomando por base a teoria existente é essencial para dar significado às respostas.

A pesquisa abrangeu a empresa Métodos Contabilidade, situada na cidade do Natal no estado do Rio Grande do Norte, e atuante no mercado há mais de 25 anos, com serviços de contabilidade abrangendo a área fiscal, pessoal, contábil e legalização, além dos serviços de consultoria e integração de softwares. A referida empresa possui 37 colaboradores e uma carteira significativa de clientes. A empresa tem um porte inovador, onde apresentou na metodologia do radar da inovação, em relação a 48 empresas analisadas, o maior grau de inovação, tendo destaque na dimensão Processos.

Como instrumento de coleta de dados, foi utilizado, inicialmente, um questionário, denominado de radar da inovação e uma entrevista semiestruturada que foi realizada em profundidade. O radar, baseado em Bachman e Destefani (2008), mede o grau de inovação considerando treze dimensões: Marca, Plataforma, Oferta, Clientes, Organização, Soluções, Cadeia de Fornecimento, Rede, Agregação de Valor, Presença, Processos, Clientes e Ambiência Inovadora. Este instrumento possui 35 questões, mensuráveis por meio de uma escala de cinco pontos, que apresenta como resultado de sua mensuração uma caracterização do grau de inovação das empresas. Com o instrumento do radar da inovação, pode-se medir o grau de inovação da empresa estudada neste artigo em relação a seus concorrentes. Foi utilizado no presente trabalho como forma de caracterizar o grau de inovação três scores, 1- a inovação não está presente, 3- a inovação é incipiente, 5- a inovação está presente. Este instrumento foi aplicado no período de 06/05/2014 a 27/02/2015 com 48 empresas contábeis.

Já a entrevista foi baseada no modelo de Rezende (2005), onde são tratados os principais benefícios relacionados à inovação nas empresas. Ela teve uma duração média de 4,5 horas e foi realizada com os três gestores da empresa separadamente. A técnica utilizada na análise e tratamento dos dados foi a técnica de análise de conteúdo que consiste, segundo Michael (2009), em "descrever, registrar, analisar e comparar comunicações de massa" e algumas formas de utilizar a análise de conteúdo consiste em descrever tendências no conteúdo das comunicações, comparar níveis, mensagens e meios de comunicação, aplicar e construir padrões de comunicação, criticar 
conteúdos de comunicações, medir a clareza das mensagens, identificar intenções de comunicadores, descobrir estilos de comunicação, dentre outros aspectos.

De acordo com a técnica proposta pela autora, a análise de conteúdo realiza levantamento de dados que utiliza falas, textos e informações já coletadas, de forma extensiva, posteriormente a coleta. A proposta desta análise é aprofundar a análise de conteúdo referente às informações prestadas pelos indivíduos que forneceram os dados, buscando ver e analisar, com maior profundidade, a pertinência, coerência e lógica das respostas, bem como a fidedignidade dos dados informados, eventuais distorções ou até mesmo omissões voluntárias. Desta forma, as informações levantadas nesta pesquisa foram simplificadas para efeito de comparação, através da descrição dos principais benefícios das inovações em processos que a empresa implantou, de acordo com a percepção de cada entrevistado. Em seguida, foram levantados os resultados convergentes e divergentes do modelo de Rezende (2005) acerca dos benefícios alcançados.

\section{RESULTADOS E DISCUSSÕES}

Tendo como objetivo geral analisar os benefícios das inovações em processos em escritórios de contabilidade, através do uso do sistema de informação e da tecnologia da informação, será analisada, através das ilustrações abaixo, a quantidade de benefícios que a empresa Métodos Contabilidade adquiriu inovando em processos através da tecnologia da informação. As mudanças no cenário contábil estão acontecendo de uma maneira rápida, NF-e, SPED, e-SOCIAL, são alguns exemplos de mudanças no cenário brasileiro, onde o profissional contábil precisa adapta-se de uma maneira rápida para acompanhá-las, e todas essas mudanças estão afetando os processos internos das empresas contábeis no país, sendo necessário que as organizações se adaptem a esta realidade, realizando inovações, principalmente nos processos das empresas.

A Métodos Contabilidade procura realizar investimentos em hardwares e softwares para melhoria dos processos da empresa, garantindo um diferencial competitivo. Conforme a Tabela 1 verifica-se que a empresa tem um significativo destaque na dimensão Processos, em comparação com 48 empresas contábeis analisadas nesta dimensão. Essa importância que a empresa atribui à dimensão processos está justificada pelos benefícios que a inovação em processos traz para a Métodos, conforme as figuras seguintes.

Tabela 1 - Comparativo do Radar da inovação e da Dimensão Processos

\begin{tabular}{c|c|c|c}
\hline $\begin{array}{c}\text { Média Global Radar da } \\
\text { Inovação (48 empresas) }\end{array}$ & $\begin{array}{c}\text { Radar da Inovação } \\
\text { Métodos }\end{array}$ & $\begin{array}{c}\text { Média Global Dimensão } \\
\text { Processos (48 } \\
\text { empresas) }\end{array}$ & $\begin{array}{c}\text { Dimensão } \\
\text { Processos Métodos }\end{array}$ \\
\hline 2.1 & 3.1 & 1.8 & 3.3 \\
\hline
\end{tabular}

No que se refere ao Radar da Inovação, fazendo uma comparação da média geral das 48 empresas analisadas com o score obtido pela empresa Métodos Contabilidade, visualiza uma pontuação média de 3.1, ante 2.1, que é o valor médio obtido pelas demais empresas do segmento. Da mesma forma acontece com a Dimensão Processos, em que a empresa Métodos demonstra um avanço de 3.3 pontos nesta dimensão, maior do que a média das demais empresas do segmento, que obtiveram um valor médio de 1.8. Todos esses resultados mostram que a empresa investe em 
inovações em Processos e procura inovar nesta dimensão, em função dos benefícios obtidos, tornando um diferencial competitivo para a empresa. A Figura 2 expõe os benefícios das inovações em processos que a empresa implantou, na visão de cada entrevistado da pesquisa:

\begin{tabular}{|c|c|c|}
\hline ENTREVISTADO 1 & ENTREVISTADO 2 & ENTREVISTADO 3 \\
\hline 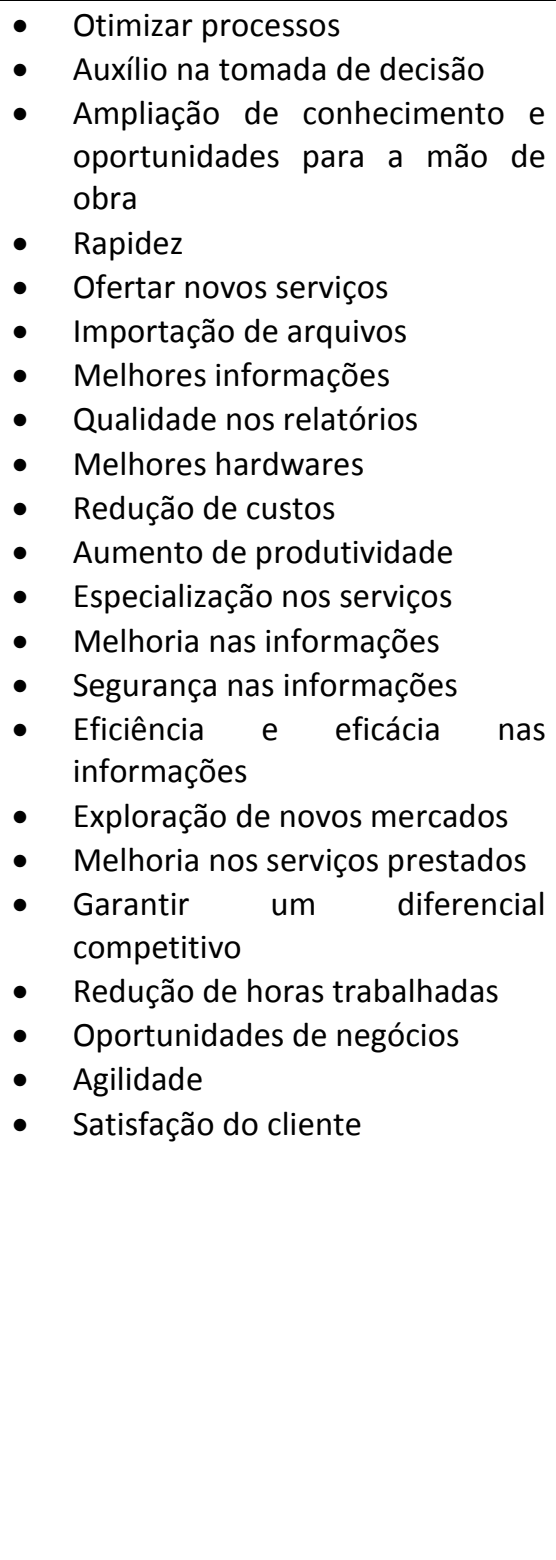 & 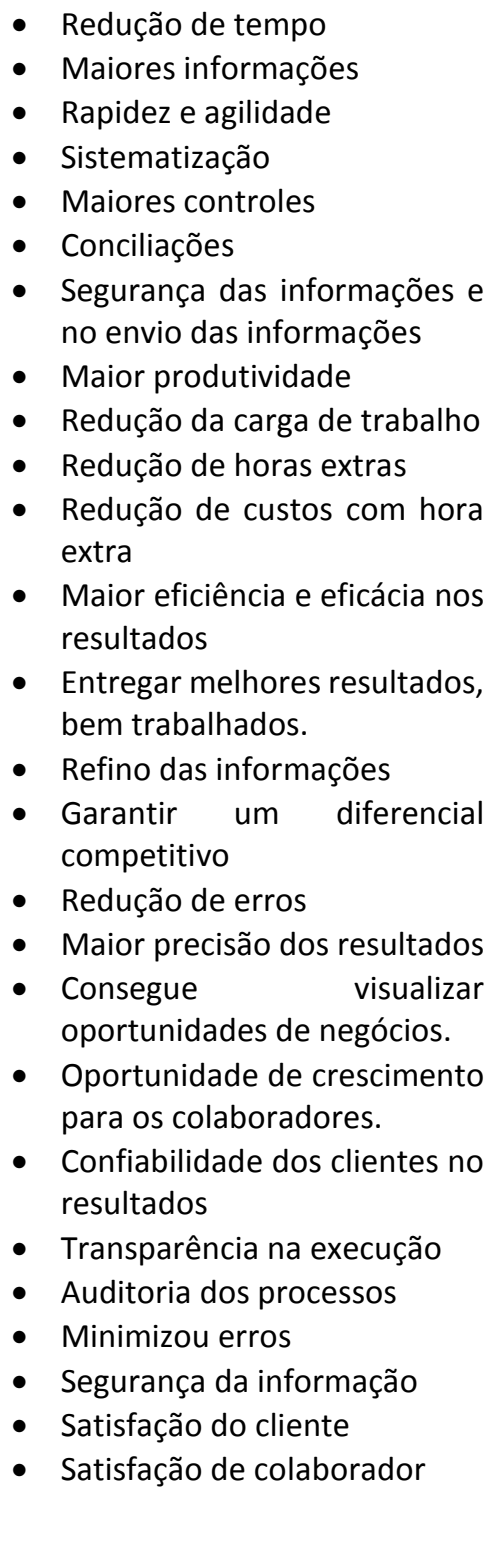 & 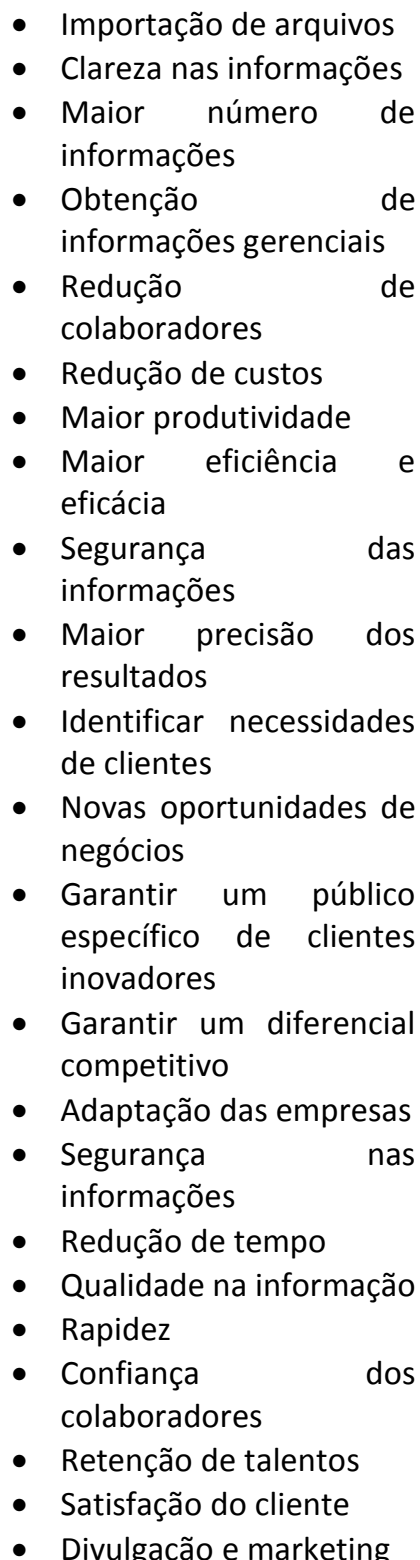 \\
\hline
\end{tabular}

Figura 2 - Benefícios das Inovações em processos através dos sistemas de informação e da tecnologia da informação na visão dos gestores

Fonte: Dados da Pesquisa 2015

Conforme a Figura 2 existe uma quantidade significativa de benefícios que as inovações em processos, através dos sistemas de informação e da tecnologia da informação, trazem para a empresa estudada. De acordo com os três dirigentes da empresa, todos elencaram a rapidez, maior eficiência e eficácia, segurança das informações, satisfação dos clientes, redução de erros, maior produtividade, garantia de diferencial competitivo, conquista de novos mercados, maior precisão dos resultados, qualidade nas informações, como benefícios que foram alcançados através das inovações em processos que a empresa realizou através dos sistemas de informação e da tecnologia 
da informação. Estes resultados refletem a importância das empresas contábeis inovarem em processos, pois a garantia de benefícios é significativa e as mudanças que estão ocorrendo neste segmento, precisam ser acompanhadas, existindo a necessidade de inovar em processos, principalmente através da tecnologia da informação, que garante benefícios mensuráveis.

O próximo passo da análise se refere ao levantamento dos benefícios gerados pelo incremento da inovação nos processos de negócio da empresa pesquisada, através da comparação com os aspectos levantados por Rezende (2005), onde são apresentados os resultados convergentes e divergentes em relação à teoria proposta, descritas na Figura 3 abaixo.

De acordo com os dados obtidos, pode-se observar que os benefícios alcançados com inovação de processos, através dos sistemas de informação e da tecnologia da informação, se apresentaram de uma maneira significativa, estando de acordo com a teoria proposta por Rezende (2005) e apresentando alguns resultados que não estão presentes na teoria colocada pelo autor. A empresa identificou outros benefícios como a especialização nos serviços, satisfação do cliente, transparência na execução, auditoria dos processos, satisfação de colaborador, obtenção de informações gerenciais, redução de colaboradores, garantirem um público específico de clientes inovadores, adaptação das empresas, confiança dos colaboradores, retenção de talentos e divulgação e marketing.

\begin{tabular}{|c|c|c|}
\hline Resumo dos benefícios da empresa & $\begin{array}{c}\text { Resultados convergentes com } \\
\text { Rezende (2005) }\end{array}$ & $\begin{array}{c}\text { Resultados divergentes de } \\
\text { Rezende (2005) }\end{array}$ \\
\hline $\begin{array}{l}\text { - Otimizar processos } \\
\text { - Auxílio na tomada de decisão } \\
\text { - Ampliação de conhecimento e } \\
\text { - Agilidade e rapidez } \\
\text { - Ofertar novos serviços } \\
\text { - Importação de arquivos } \\
\text { - Qualidade nos relatórios } \\
\text { - Melhores hardwares } \\
\text { - Redução de custos } \\
\text { - Aumento de produtividade } \\
\text { - Especialização nos serviços } \\
\text { - Melhoria nas informações prestadas } \\
\text { - Segurança nas informações } \\
\text { - Eficiência e eficácia nos resultados } \\
\text { - Exploração de novos mercados } \\
\text { - Melhoria nos serviços prestados } \\
\text { - Garantir um diferencial competitivo } \\
\text { - Redução de horas trabalhadas } \\
\text { - Satisfação do cliente } \\
\text { - Sistematização } \\
\text { - Maiores controles } \\
\text { - Renciliações } \\
\text { - Regurança das informações } \\
\text { - Redução de horasa extras de custos com hora extra } \\
\text { - Ras informações }\end{array}$ & $\begin{array}{l}\text { - A oferta de melhores } \\
\text { - } \text { Obterviços } \\
\text { vantagão de uma maior } \\
\text { - } \text { Contribuição na } \\
\text { inteligência } \\
\text { organizacional, } \\
\text { - } \text { Auxílio à tomada de } \\
\text { - decisão útil } \\
\text { - Produtos de melhor } \\
\text { - } \text { qualidade } \\
\text { - } \text { novas oportunidades de } \\
\text { - Maior segurança nas } \\
\text { - } \text { informações } \\
\text { - } \text { Melhor precisão e } \\
\text { - } \text { Aperfeiçoamento nos } \\
\text { - } \text { sistemas } \\
\text { - Redução de custos } \\
\text { - } \text { trabalhão da carga de } \\
\text { Melhor eficiência e } \\
\text { eficácia }\end{array}$ & 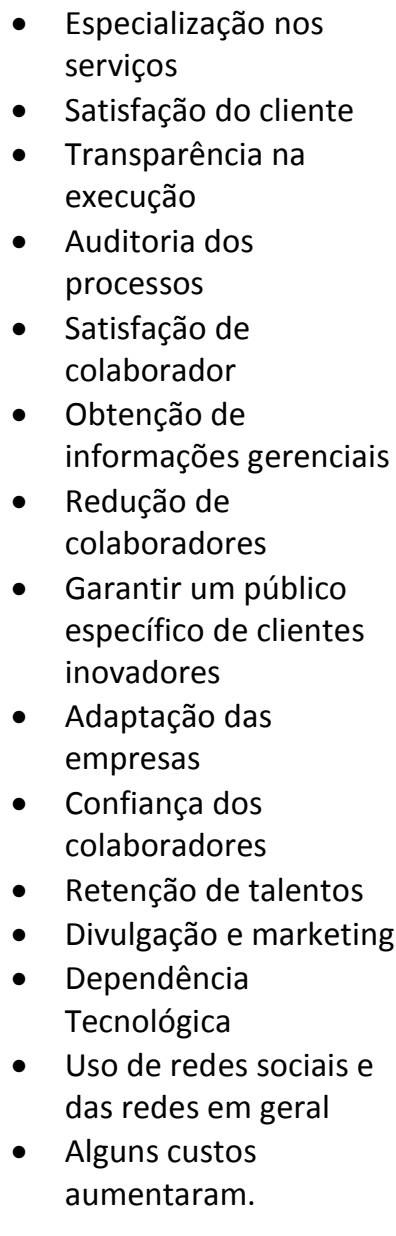 \\
\hline
\end{tabular}


- Redução de erros

- Maior precisão dos resultados

- Oportunidade de crescimento para os colaboradores.

- Confiabilidade dos clientes no resultados

- Transparência na execução

- Auditoria dos processos

- Satisfação de colaborador

- Clareza nas informações

- Obtenção de informações gerenciais

- Redução de colaboradores

- Identificar necessidades de

- Garantir um público específico de clientes inovadores

- Adaptação das empresas

- Confiança dos colaboradores

- Retenção de talentos

- Divulgação e marketing

Figura 3 - Benefícios gerais das Inovações em processos através dos sistemas de informação e da tecnologia da informação

Fonte: Dados da Pesquisa 2015

Também foram identificados, por um dos gestores da empresa estudada, pequenos pontos negativos das inovações em processos, através dos sistemas de informação e da tecnologia da informação, como a grande dependência dessas tecnologias, em que, caso ocorra alguma falha, o trabalho da organização fica prejudicado, identificou também um maior uso de redes sociais e das redes em geral e que alguns custos aumentaram. Porém, foi considerado que os benefícios superam, significativamente, esses eventuais pontos negativos que as inovações em processos podem apresentar e demonstra também que o diferencial obtido no radar da inovação, na dimensão Processos, é justificado pelos maiores benefícios que esse tipo de inovação traz para a empresa.

\section{CONCLUSÕES}

O presente estudo teve como objetivo geral analisar os benefícios das inovações em processos, nos escritórios de contabilidade, através do uso do sistema de informação e da tecnologia da informação. Quanto aos procedimentos foi realizado um estudo de caso único, com a empresa Métodos Contabilidade, foi feito um estudo, predominantemente, qualitativo. Foi utilizado um questionário, denominado de radar da inovação e uma entrevista semiestruturada que foi realizada em profundidade.

Os resultados encontrados estão de acordo com a teoria proposta, mensurando-se um número significativo de benefícios que a inovação de processos, através dos sistemas de informação e da tecnologia da informação, traz para uma organização. Foi demonstrado que a empresa, objeto de estudo, apresenta um alto grau de inovação em processos, medida através do radar da inovação, em comparação com 48 empresas contábeis e este destaque é resultado do número de benefícios que são alcançados através da tecnologia da informação. 
A necessidade das empresas contábeis inovarem em processos é de suma importância para o crescimento e a sustentabilidade das empresas. As mudanças estão acontecendo de uma maneira rápida, sendo necessário que as organizações acompanhem este cenário e se adaptem a esta realidade, realizando inovações, principalmente nos processos das empresas. Uma importante ferramenta para a inovação em processos são os sistemas de informação com o uso da tecnologia da informação, que geram benefícios significativos e de uma maneira rápida.

Esses benefícios foram demonstrados neste artigo, através de um estudo de caso com uma empresa que tem como foco principal a inovação em processos, demonstrado pelo excelente score obtido frente às demais empresas, referente à dimensão processos. Foi elencado um número extenso de benefícios alcançados com as inovações em processos através dos sistemas de informação com o uso da tecnologia da informação para a empresa e os benefícios encontrados estão de acordo com a teoria estudada.

Dentre as limitações do trabalho, pode-se destacar que pelo fato de o estudo ter sido realizado por meio de um caso único não gerando possibilidade de comparação entre outras empresas de contabilidade, todavia, esta limitação não compromete o resultado da presente pesquisa, uma vez que, para estudos futuros, podem ser analisadas as inovações em processos em empresas de contabilidade de menor porte em comparação com as empresas de maior porte. Também se faz necessário estabelecer uma análise comparativa, levando em consideração outros segmentos do mercado, no intuito de encontrar outros aspectos relevantes da inovação em processos.

\section{REFERÊNCIAS}

1. ANDRADE, A. C. et al. Políticas de segurança em sistemas de informação contábil: um estudo em cooperativas de crédito do estado de Minas Gerais. Revista Contemporânea de Contabilidade - Florianópolis, v.4 n.7, 125-143, jan-jun. 2007.

2. BACHMANN, D. L. E DESTEFANI, J. H. Metodologia para estimar o grau das inovações nas MPE: cultura do empreendedorismo e inovação. Curitiba: SEBRAE, 2008.

3. BEUREN, I. M. Evolução histórica da contabilidade de custos. Contabilidade Vista e Revista Belo Horizonte, v. 5, n. 1, 61-66, fev. 1993.

4. BORGES, R. D. O. Tecnologia e Sistemas de Informação e Suas Influências na Gestão. IX SEGEC 2012 - Simpósio de Excelência em Gestão e Tecnologia. 2012.

5. BURREL, G.; MORGAN, G. Sociological paradigms and organisational analysis: elements of the sociology of corporate life. Vermont: Ashgate, 1979.

6. BYRD, T. A.; TURNER, D. E. Measuring the flexibility of information technology infrastructure: exploratory analysis of a construct. Journal of Management Information Systems - Saddle River, v. 17, n.1, 167-208, jan-dez. 2000.

7. CONSELHO FEDERAL DE CONABILIDADE (CFC). Pesquisa perfil do profissional da contabilidade 2012/13. (2013). Disponível em: < http://portalcfc.org.br/wordpress/wpcontent/uploads/2013/12/livro_perfil_2013_web2.pdf>. Acesso em: 09 set. 2014. 
8. CORREIA, F. D. O sistema de informação para a contabilidade. 2013. Disponível em: $<$ http://www.webartigos.com/artigos/o-sistema-de-informacao-para-acontabilidade/68718/>. Acesso em: 12 out. 2014.

9. FLICK. U. Introdução à pesquisa qualitativa. 3. ed. Porto Alegre: Artmed, 2009.

10. GRZESZEZESZYN, G. Contabilidade gerencial estratégica: conceito e caracterização. Revista Capital Científico - Guarapuava, v. 3, n.1, 09-27, jan-dez. 2005.

11. HENDERSON, J. C.; VENKATRAMAN, N. Strategic alignment: leveraging information technology for transforming organizations. IBM Systems Journal - New York, v. 32 n.1, 111-142, jan-dez. 1993.

12. KIRCHMER, M. Management of Process Excellence. In: VOM BROCKE, J.; ROSEMANN, M Org.). Handbook on business process management 2: strategic alignment, governance, people and culture. New York: Springer, 2010, p. 39-56.

13. LAUDON, K. C.; LAUDON, J. P. Sistemas de informação gerenciais: administrando a empresa digital. 5. ed. São Paulo: Prentice Hall, 2004.

14. LEITE, F. T. Metodologia científica: métodos e técnicas de pesquisa. 2. ed. Aparecida, SP: Idéias \& Letras, 2008.

15. LONGANEZI, T. Os sistemas de gestão da inovação e a capacidade inovadora das empresas. 2008. Tese (Doutorado) - Curso de Engenharia Química, Escola de Química da Universidade Federal do Rio de Janeiro, Rio de Janeiro.

16. MARION, J. C. A Profissão Contábil no Brasil. 2014 Disponível em: <http://fesppr.br/ teo guenes/artigos/profissao_contabil_no_brasil.pdf >. Acesso em: 22 set. 2014.

17. MENDONÇA, C. M. C. et al. Governança de tecnologia da informação: um estudo do processo decisório em organizações públicas e privadas. Revista de Administração Pública (RAP) - Rio de Janeiro, v. 47, n. 2, 443-468, mar-abr. 2013.

18. MICHAEL, M. H. Metodologia e pesquisa científica em ciências sociais. 2. ed. São Paulo: Atlas, 2009.

19. OCDE. Manual de Oslo: diretrizes para coleta e interpretação de dados sobre inovação. 3. ed. Rio de Janeiro: FINEP, 2007.

20. PADOVEZE, C. L. Sistemas de informações contábeis: fundamentos e análise. 2. ed. São Paulo: Atlas, 2000.

21. PIERRY, Luiz. Ildebrando. Inovação como diferencial competitivo no mercado globalizado. Porto Alegre: [s.n.], 2001. Disponível em: <http://www.enfato.com.be/artigos_det.php?tutu lo=10> . Acesso em: 02 fev. 2015.

22. REIS, A. J.; SILVA, S. L. A história da contabilidade no Brasil. 2007. Disponível em: <http://tupi.fisica.ufmg.br/michel/docs/Artigos_e_textos/Ciencias_Contabeis/historia\%20da \%20contabilidade\%20no\%20Brasil.pdf > Acesso em: 22 set. 2014.

23. REZENDE, D. A. Engenharia de Software e Sistemas de Informação. 3. ed. Rio de Janeiro. Brasport, 2005.

24. REZENDE, D. A., ABREU, A. F., Tecnologia da Informação aplicada a sistemas de informação empresariais: o papel estratégico da informação e dos sistemas de informação nas empresas. 
São Paulo: Atlas, 2000.

25. SANTOS, M. C. D. Fundamentos do sistema de informação. [2012]. Disponível em: <http://www.profdamasco.site.br.com/SlidesFundamentosSI.pdf>. Acesso em: 22 set. 2014.

26. SCHOLTISSEK. S. Excelência em Inovação: como criar mercados promissores nas áreas energéticas e de recursos naturais. Rio de Janeiro: Elsevier, 1959.

27. SOUZA, G. L. Gestão da difusão de inovações no mercado em micro e pequenas empresas brasileiras: estudo de uma vencedora do prêmio Finep de inovação. 144 f. Dissertação (Mestrado em Administração) - Núcleo de Pós-graduação em Administração da Universidade Federal da Bahia, Salvador, 2011.

28. YIN, R. K. Estudo de caso: planejamento e métodos. 3. ed. Porto Alegre: Bookman, 2005.

29. ZWIRTES, A.; ALVES, T. W. Os Impactos Causados pela Inovação Tecnológica em Escritórios de Contabilidade do Rio Grande do Sul: uma Análise Fatorial. Revista de Educação e Pesquisa em Contabilidade - Brasília, v. 8, n.1, 39-53, jan-mar. 2014. 